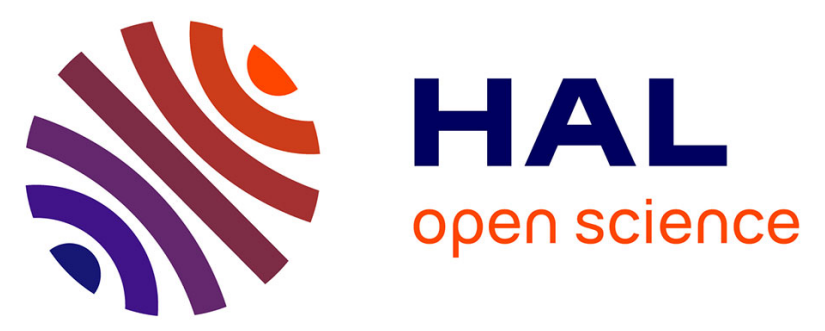

\title{
STEM 3.0 for Chinese Students with Sea Perch Underwater Robots: An Experimental Summer Camp for Hands-on Thinkers in Shanghai
}

Ang Li, Yi Yu, Gurvan Jodin, Dixia Fan, Huimei Xie, Chong Sun, Subi Lijia $\mathrm{Gu}$. . Coco, Jieqiong $\mathrm{Xu}$

\section{To cite this version:}

Ang Li, Yi Yu, Gurvan Jodin, Dixia Fan, Huimei Xie, et al.. STEM 3.0 for Chinese Students with Sea Perch Underwater Robots: An Experimental Summer Camp for Hands-on Thinkers in Shanghai. 2020 IEEE Global Engineering Education Conference (EDUCON), Apr 2020, Porto, France. pp.133-138, 10.1109/EDUCON45650.2020.9125317 . hal-03099402

\section{HAL Id: hal-03099402 https://hal.science/hal-03099402}

Submitted on 19 Jan 2021

HAL is a multi-disciplinary open access archive for the deposit and dissemination of scientific research documents, whether they are published or not. The documents may come from teaching and research institutions in France or abroad, or from public or private research centers.
L'archive ouverte pluridisciplinaire HAL, est destinée au dépôt et à la diffusion de documents scientifiques de niveau recherche, publiés ou non, émanant des établissements d'enseignement et de recherche français ou étrangers, des laboratoires publics ou privés. 


\section{STEM 3.0 for Chinese Students with Sea Perch Underwater Robots: An Experimental Summer Camp for Hands-on Thinkers in Shanghai}

\author{
Ang Li, Yi Yu \\ MOE Key Laboratory of Hydrodynamics, \\ Department of Naval Architecture, Ocean and \\ Civil Engineering \\ Shanghai Jiaotong University \\ Shanghai, China \\ greatang@sjtu.edu.cn, \\ yu yi2012@sjtu.edu.cn, \\ Huimei Xie, \\ Department of Naval Architecture, Ocean and \\ Civil Engineering \\ Shanghai Jiaotong University \\ Shanghai, China \\ hm.xie@sjtu.edu.cn
}

\author{
Gurvan Jodin \\ SATIE \\ ENS Rennes, CNRS \\ Bruz, France \\ gurvan.jodin@ens-rennes.fr
}

Chong Sun

State Key Laboratory of Hydraulic Engineering Simulation and Safety

Tianjin University

Tianjin, China

chong@tju.edu.cn

\author{
Dixia Fan* \\ Department of Mechanical Engineering \\ Massachusettes Institute of Technology \\ Cambridge, USA \\ dfan@mit.edu
}

\author{
Subi Lijia Gu, CoCo, Jieqiong $\mathrm{Xu}$ \\ line 2: dept. name of organization (of \\ Affiliation) \\ Shanghai Little Greenbot Ltd. \\ Shanghai, China \\ ddsds@mit.edu, deded@mit.edu
}

\begin{abstract}
In the last 5 years, we see a drastically increasing demand and interest in the STEM education from every aspect of Chinese public and private educational sectors. However due to the short-time development and hence a lack of experience, Chinese STEM education faces two major challenges: the lack of the student engagement and the lack of the teaching guidelines. Therefore, we propose a new idea of "STEM 3.0" teaching methods and its corresponding classroom framework. Using an underwater robot called "Sea Perch", we then tested and implemented the concept two experimental science summer camps of more than 120 students at Shanghai in the summer of 2019. The camp is successful manifestation of the "STEM 3.0" teaching and learning method, featuring encouragingly positive student feedbacks.
\end{abstract} Robot.

Keywords-STEM, China, Hands-on Education, Underwater

\section{INTRODUCTION}

\section{A. Current Development in Chinese STEM Education}

STEM education stands for training in science, technology, engineering and mathematics. The model encourages students to apply abstract knowledge, make improvements and innovations, design and manage projects, hone their logic and analytical capability and instill in them a multi-faceted mindset. It helps to train students to solve practical problems using multidisciplinary solutions in real-life situations. STEM education has been extensively promoted and studied during the past decade [1-4]. With the fast development of modern technology, the way of STEM educating is in a continuous revolution. With the help of the increasing [5] computer resources, for example, in Europe, teachers attempt to give STEM instructions via the exploitation of UMI technologies (Ubiquitous Computing, Mobile Computing and the Internet of Things) [6]. Therefore, the classes are extended from school to home [7], and we can find numerous curriculums and products are developed for $\mathrm{k}-12$ [8-10].

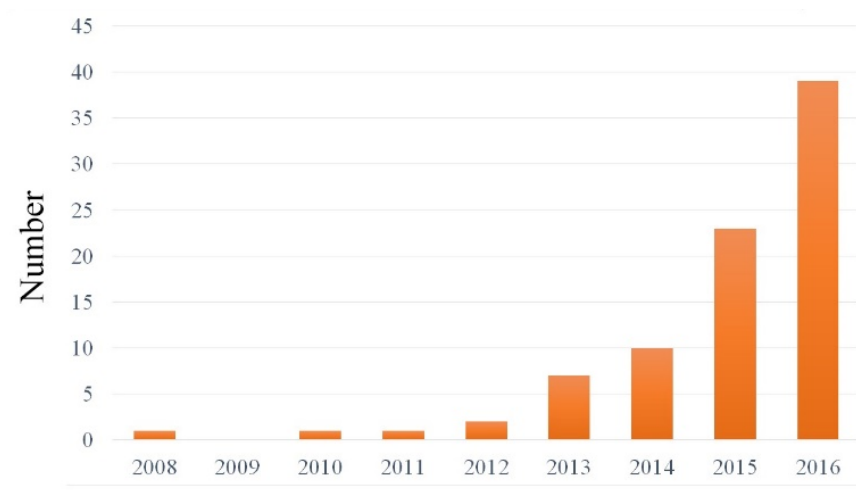

Fig. 1. The increasing number of published paper related to the topic of STEM education in China [13].

In the meantime, after almost 40 years since the first national university entrance examination held in 1977 [11], in the last ten years, we see a swiftly growing interest from all aspects of Chinese educational sectors in the reform of the traditional exam-orientated, subject-learning education style to a system with an increasing emphasis on the hands-on practicing of knowledge using. One of the most popular ideas is STEM education, which was first introduced into China in 2001. The STEM education industry started booming from 2012 [12], as we saw an appearance of thousands of private and public sectors 
promoting the education of STEM subjects, such as coding, robotics, etc. Simultaneously, the number of researches on STEM education are rapidly growing, demonstrated by the increase number of research papers of STEM education topics, shown in Fig. 1. Furthermore, in 2016, the Chinese government has integrated the STEM concept into the national science and technology strategy, as a number of policies encouraging reform of traditional education are issued [12].

\section{B. Challenges in Chinese STEM Education}

Despite the public hype on STEM education, we saw many challenges facing Chinese STEM educators[14,15]. To begin with, the STEM education developed in China only for a very short time, and therefore, there is a lack of high-quality teachers, class subjects, and educational culture. However, most importantly, Chinese STEM education faces two significant challenges. The first point is the lack of engagement from the student, as the Chinese students are used to play the role of the receiver instead of the participant in the class, and, besides, they do not have much experience in the hands-on practice. The second challenge is the lack of the teaching structure for the STEM educator, as the Chinese teachers in the public education system are used to be the knowledge giver, and they will use the same methods to teach the STEM subjects with a focus on the knowledge learning and examination skills.

Therefore, we proposed the idea of "STEM 3.0", and implemented such a learning and teaching method in an experimental summer camp in Shanghai for hands-on thinkers, based on an underwater robot called "Sea Perch". In this paper, we first describe in detail the idea and the classroom implementation of "STEM 3.0", followed by the lesson we learned from the 2019 summer camp.

\section{STEM 3.0: TASK-BASED LEARNING}

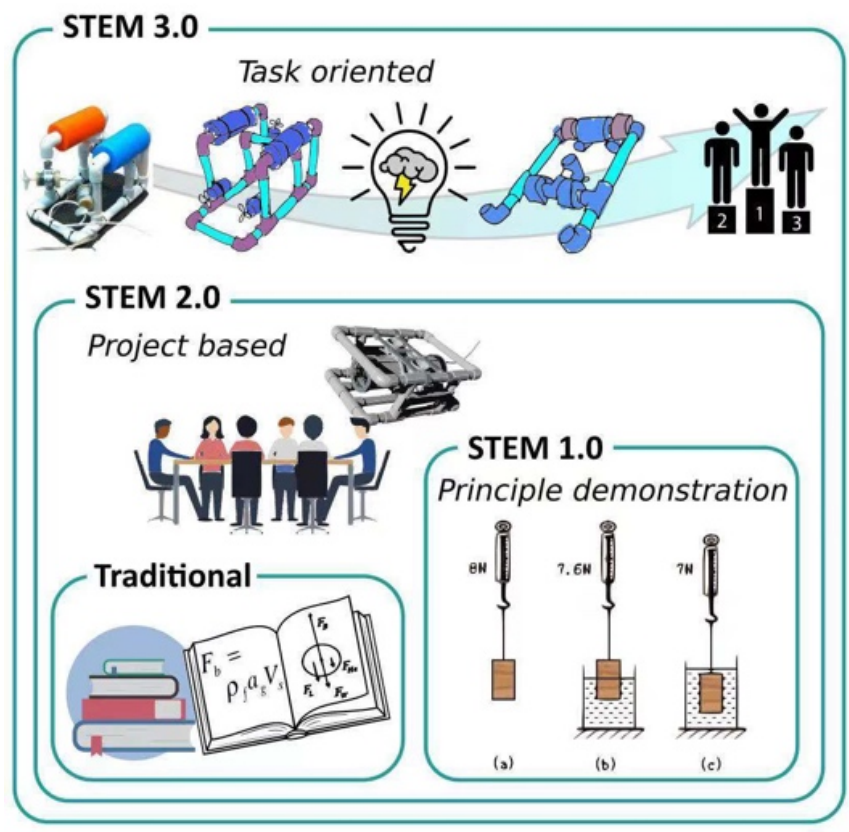

Fig. 2. Concept of the "STEM 3.0" learning and teaching method and its relationship to the "Traditional", "STEM 1.0" and "STEM 2.0" methods.
"STEM 3.0", a concept of teaching for Chinese students, is evolved from can be dated back to Prof. Harold "Doc" Edgerton's idea (early 50s) [16] of learning via scientific principle demonstration using interactive devices ("STEM 1.0") and Prof. Kim Vandiver's vision (late 90s and early 00s) [17] on hands-on learning experience via a well-defined step-by-step project ("STEM 2.0"). As an improvement from "STEM 1.0 \& 2.0", "STEM 3.0" keeps and includes major elements and therefore stays a close relationship with "STEM $1.0 \& 2.0$ ". In detail, we believe that in order to better teach STEM subjects to students, instructors first need to use interactive scientific demonstrations and step-by-step projects to prepare students with required theoretical and practical backgrounds, and then via the announcement of a given task for a real-world problem simulated in labs to encourage the students as hands-on thinkers to find their creative solutions.

Fig. 2 demonstrated the concept of "STEM 3.0" teaching and learning method and describe its relationship with the "Traditional," "STEM 1.0" and "STEM 2.0" methods, using an example of the education in the subject of ocean engineering. Taking the concept of hydrostatics as an example, the "Traditional" method focuses on the learning of the scientific concept from the book reading or classroom lecturing, and homework of various problem sets on the calculation of the buoyancy force and center of buoyancy will be assigned to students to reinforce their understanding of the theory. Instead, the "STEM 1.0" method encourages to conduct laboratory experiments using interactive devices that students can have a vivid demonstration of how Archimedes law is applied in the real world. Instead of focusing on the knowledge learning, the "STEM 2.0" method advocates students' active engagement of finishing a hands-on, step-by-step project. In order to successfully build a low-cost underwater robot "Sea Perch" (the technological and educational details of "Sea Perch" will be given in the next section.), students will need to understand the concept of hydrostatics as a prerequisite and know how to use it in a real-world application. Fully engaged in the build-test-build process, students "do not know" that they have already acquired the scientific concept. However, nowadays, we believe the learning process should be extended further as a "STEM 3.0" learning experience. Instead of ending the class with the completion of the step-by-step projects, for example, an underwater robot, the instructor will provide students with a realworld problem/task that can be simulated in the classroom and encourage students to find solutions by integrating their ideas into the standard project they just finished, For example, for an underwater robot class, task of cleaning the oil pollution after deep water horizon catastrophe (the oil pollutant can be replaced by black ping-pong balls.) can be assigned to the students.

In detail, the process of implementing the "STEM 3.0" teaching and learning method is summarized and plotted as a flowchart in Fig. 3, and the key elements are listed out as well. The major four steps of "STEM 3.0" are Introduction, Projectbased Learning, Task Solving, and Showcase.

In the Introduction phase, a clear picture of the purpose and steps of the class should be first delivered to students. In addition, as the nature of the project and task-orientation, classes based on "STEM 3.0" require notable team-based collaboration, and therefore it is essential to construct a balanced team. We 
found that when constructing a team, it was beneficial to assign team roles to each student, such as software leader, vehicle operator, etc., and this put each team member in charge of part of the task solving process that greatly excites the student and enhances their engagement.

In the Project-based Learning phase, a step-by-step project is designed to help students to establish necessary theoretical and practical backgrounds that allow them later to finish the task individually. We found this step is especially important for Chinese students, as they are not used to such a teaching and learning style, and a lot of them are not good at handling the tools. Such a phase will quickly equip them with necessary skill sets as well as engage them with a great interest for the next task solving phase.

Shown in the red dashed box in Fig. 3, the Task Solving phase focuses on an experimentation iteration involving brainstorm, design, prototyping, field test, and analysis for students to solve a task that simulates the real-world problem. In such a phase, students collaborate in a group and are required to upgrade the prototype they build in the Project-based Learning phase and integrate their own design and inspiration to come up with their unique solution to the problem.

Last but not least, it is essential to set up a Showcase phase for the students to demonstrate their original design after they finish their task (many times, it can be formed as a competition). Besides, such a showcase is not only a demonstration but also an excellent opportunity for the students to review their activities, summarize their failures and successes, and foresee the future development. A list of questions that help the students to prepare the showcase is listed in Fig. 3.

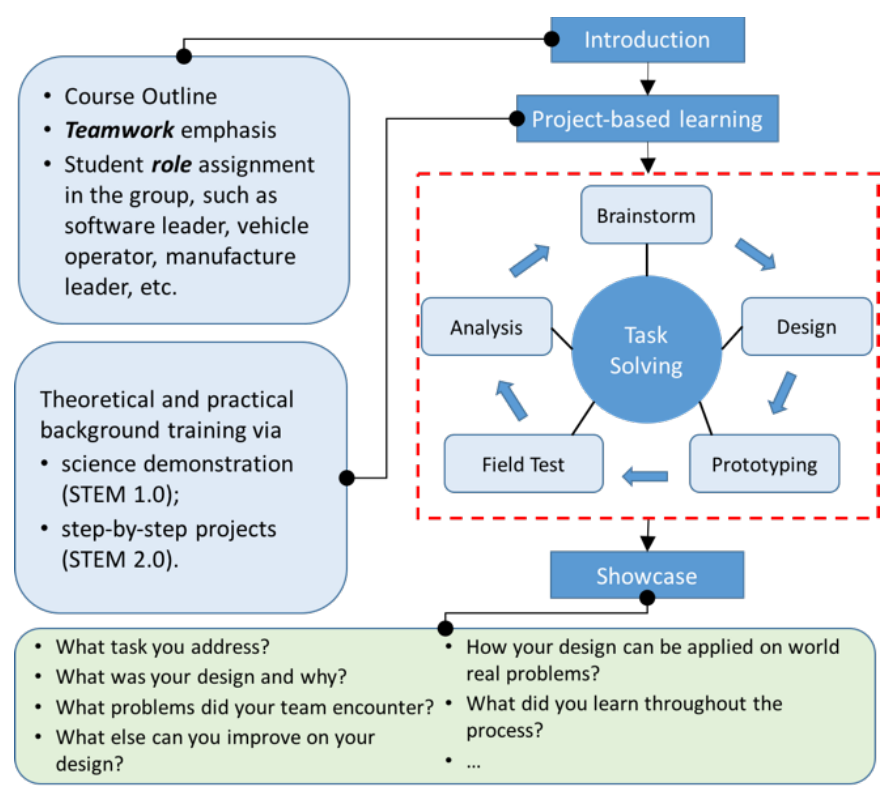

Fig. 3. Framework for the implementation of the STEM 3.0 in the classroom.

\section{IMPLEMENTATION OF STEM 3.0 IN AN EXPERIMENTAL Summer SCIENCE CAMP USING “SEA PERCH” RoBOtS}

In order to assess the validity of the "STEM 3.0" teaching method, whether it is useful in facilitating Chinese students' engagement and interest in learning STEM subjects, we implemented and tested this idea in two science camps in summer 2019 with more than 120 students attended. Each camp lasted six days, and the main project we selected for the camp is a simple underwater robot called "Sea Perch."

\section{A. A brief description of Sea Perch Robots}

The idea of "Sea Perch" was first proposed by Harry Bohm and Vickie Jensen, who wrote a book entitled "How to Build an Underwater Robot" [18]. Dr. Thomas Consi at MIT developed a curriculum around the "Sea Perch" to train their teachers and students [19].

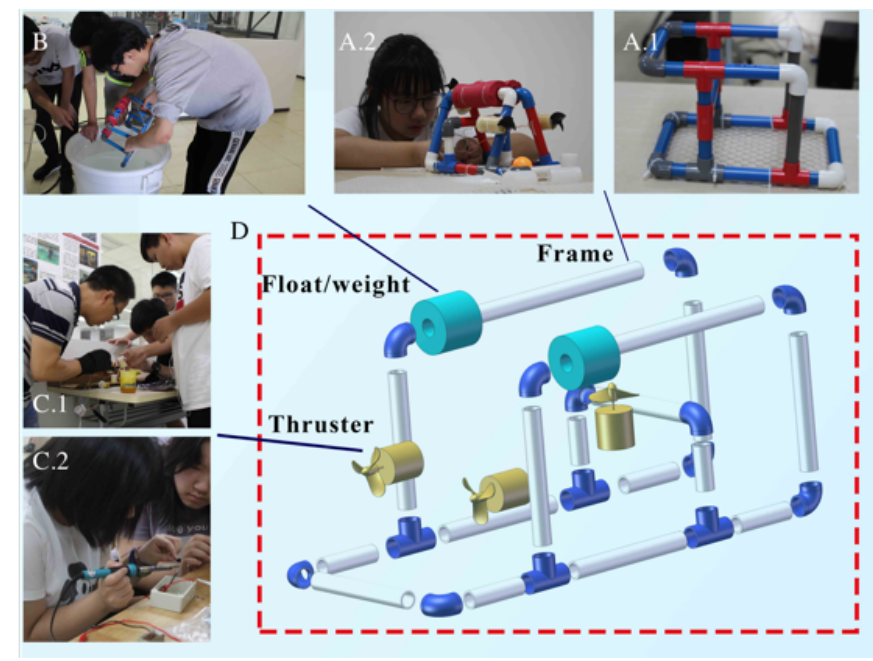

Fig. 4. Key educational components of the "Sea Perch" underwater robots. A.1 and A.2: Frame assembly for structural integrity; B: Floater placement for hydrostatics; C.1 and C.2: Motor waterproof and control box construction.

A 3D sketch of the standard "Sea Perch" robots is shown in Fig. 4 (D). The frame of the vehicle is made of PVC pipes and connectors. By constructing a standard "Sea Perch" step by step, students are well prepared to use the tools and practice hands-on skills. "Sea Perch" underwater robots can be divided into three major components, as follows,

A. Structural integrity: students are required to construct the vehicle frame with PVC pipes and connector, and at the same time to installed the model and buoyancy on the frame, shown in Fig. 4A.1 and A.2.

B. Iteration on the hydrostatic test: in order to keep the vehicle balanced underwater, students need to assemble and adjust the floats on the frame. The student is not only required to compute the buoyancy force and center of the buoyancy of the vehicle on the paper but also test it in the water, shown in Fig. 4B.

C. Thruster and control system: in the third part, students learn to waterproof the motors, shown in Fig. 4C.1, and construct the control box including soldering the wires and installing the switches, shown in Fig 4C.2. 
After finishing all steps above, the standard "Sea Perch" underwater vehicle gets ready to work. Students will then be given some time to practice the controlling in the open water area and refine their vehicles.

\section{B. Class formulation and progress}

Based on the framework of "STEM 3.0" teaching shown in Fig. 3, we arranged the 6-day camp activities as follows,

Day 1: Role assignment and theoretical background.

Day 2: Standard "Sea Perch" robot building

Day 3: Debugging and announcement of the task

Day 4-5: Group brainstorm to solve the problem

Day 6: Competition and group showtime

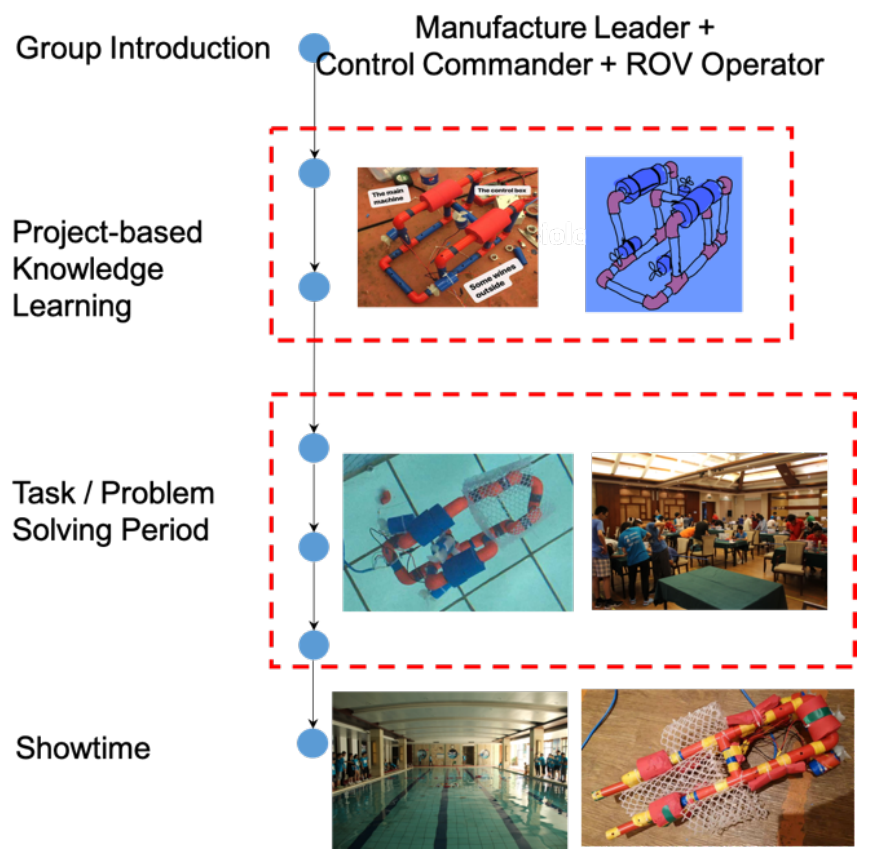

Fig. 5. Flowchart of the activies for the 2019 Sea Perch summer camp for hands-on thinkers.

These activities can be roughly divided into two phases: a. Learning the technical background with standard "Sea Perch" robot building (the first to the third day); b. Creative problem/task solving as a hands-on thinker (the third to the sixth day). We streamlined the teaching and learning activities based on the "STEM 3.0" framework for this summer camp and plot in Fig. 5. At the beginning of the camp, we first introduced the main activities to the students and divided the students into a small group of three with assigned roles as manufacture leader, control commander, and vehicle operator. Second, we introduced the standard "Sea Perch" building process and led the students to build the vehicle step-by-step with additional related scientific stories. By engaging hands-on practices, we found that the students were quickly engaged in the camp activities, get acquaintance with their teammates, and acquire basic theoretical and practical skill sets in a short time for the next phase of task/problem-solving. In the current summer camp, we provided the students with a group task of a simulated real-world problem to efficiently collect ocean plastic debris. Hence in the later competition, shown in Fig. 6, we used floating ping-pong balls to represent the ocean plastic waster, designed devices to realize the ping pang balls when the competition starts and created an environment to simulate the complicate coastal environment. With such a task announced at the end of day 3 , the students were later given two days to modify/upgrade, most of them, reconstruct the underwater vehicle based on the original standard "Sea Perch" vehicle to address the issue. On the last day of the camp, we set a stage of showcase time, and invited each group to give a 5-10 min presentation on their experience they have over the days and, more interesting, their vision to the future based on the knowledge they gained from the camp.

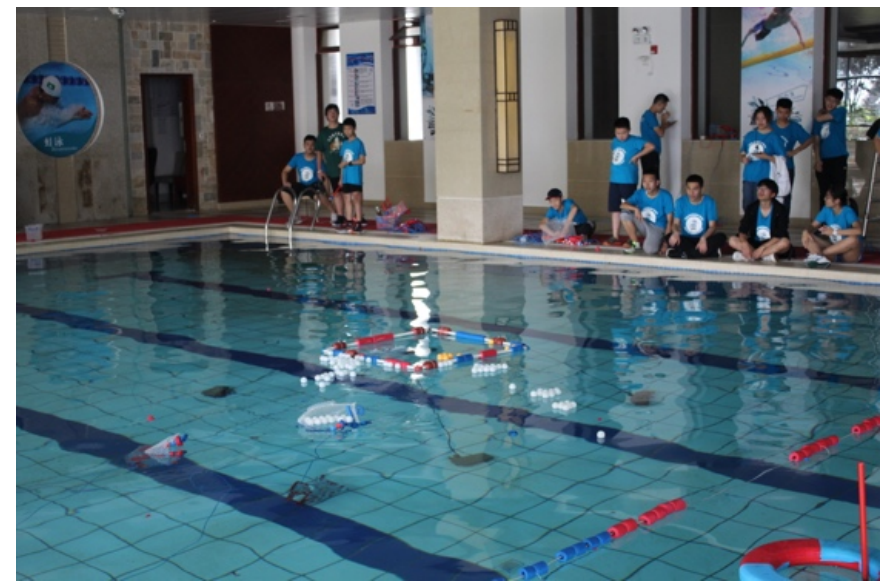

Fig. 6. Photo of students computing their personally designed underwater robots in the swimming pool to solve ocean plastic pollution problem.

In the final competition, 80 balls (each scores 1 point) are released on the open water and 20 balls (each scores 2 points) are restricted in a rectangular frame (Vehicle has to dive into the frame and bring the balls back). Each group has 8 minutes to finish the task and the scores and recorded. Table 1 shows the record of the competition (Top 3 teams and average). We also compare the average scores between the final competition and the first try by the standard vehicle, and it shows a huge improvement about $179 \%$ after the task-based project.

TABLE I. RECORD OF THE COMPETITION

\begin{tabular}{|l|l|}
\hline \multicolumn{1}{|c|}{ Item } & Score \\
\hline Rank 1 & 69 \\
\hline Rank 2 & 66 \\
\hline Rank 3 & 48 \\
\hline Average of 18 teams in the final competition & 35.2 \\
\hline Average of 18 teams in the standard ROV lesson in day 2 & 12.6 \\
\hline
\end{tabular}

Overall, we observe a high engagement of the Chinese students for the six-day activities during the summer camp. Besides, we would like first to highlight the effect of task-based learning on the students via a comparison between the underwater vehicles students made at the two phases. In Fig. 7, we plot the evolution of "Sea Perch" robot from the standard version students constructed by the third day (shown in Fig. 7A.1 and 7A.2) to student personally designed version (samples are shown in Fig. 7B.1 -- 7B.3) based on the tasks assigned to the students for the final competition. 


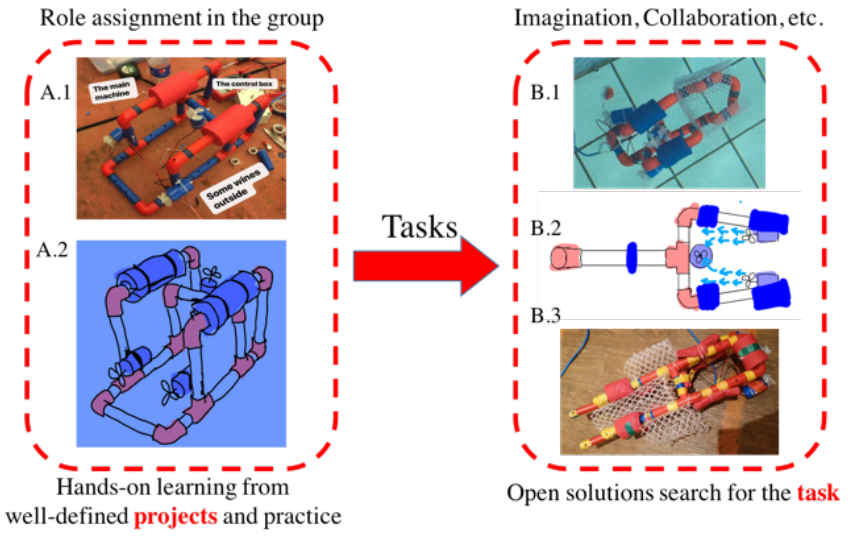

Fig. 7. Evolution of "Sea Perch" robot from the standard version (A.1 and A.2) by the end of the camp day to personally designed version based on the tasks assigned for the final competition.

We can see from Fig. 7 that compared to the standard vehicle design, the updated construction of the under vehicles from different student groups, are vastly different from each other, as students started to integrate their idea and knowledge into the vehicle design and experimentation period in order to find out "optimal" solution to the task, an open-end question. Taken the red vehicle in Fig. 7B.3 as an example, it was the winner of the first camp as it was able to collect most of the ping pong balls in a very short time, compared to its peers. The students team later summarized the four key points of their design as follows,

A. The team designed the vehicle as a long slender body, compared to the original overall rectangle shape in the hope to reduce the vehicle drag and hence increase the vehicle speed.

B. The team installed the three thrusters close to each other in order to create a strong jet wake for thrust force improvement and hence increase the vehicle speed. In the meantime, one of the propellers are modified that allows mirror rotating of the two propellers and increase maneuverability.

C. The team used the duct tapes to strengthen structural integrity, especially at the joints. This decision saved them a lot of them, as in the competition, several other teams faced challenges in wasting some time in repairing the vehicles due to the mistakes made invehicle operation.

D. The team designed special nets installed on the vehicle inspired by the pulmonary valve in a human heart that allows one-way pass. As the students observed in the test when the vehicle turned, the collected ping pong balls in the net had a high chance of slipping out of the net due to the disturbance in the water.

Such an example vividly demonstrated that, compared to the standard step-by-step project-based learning, in the task-based learning, students are not only able to put learned knowledge into practice but also integrate their knowledge of different disciplines and life experience to create their solutions to solve problems. Such an ability to use the knowledge instead of learning the knowledge alone is rare in the Chinese education system and should be improved.
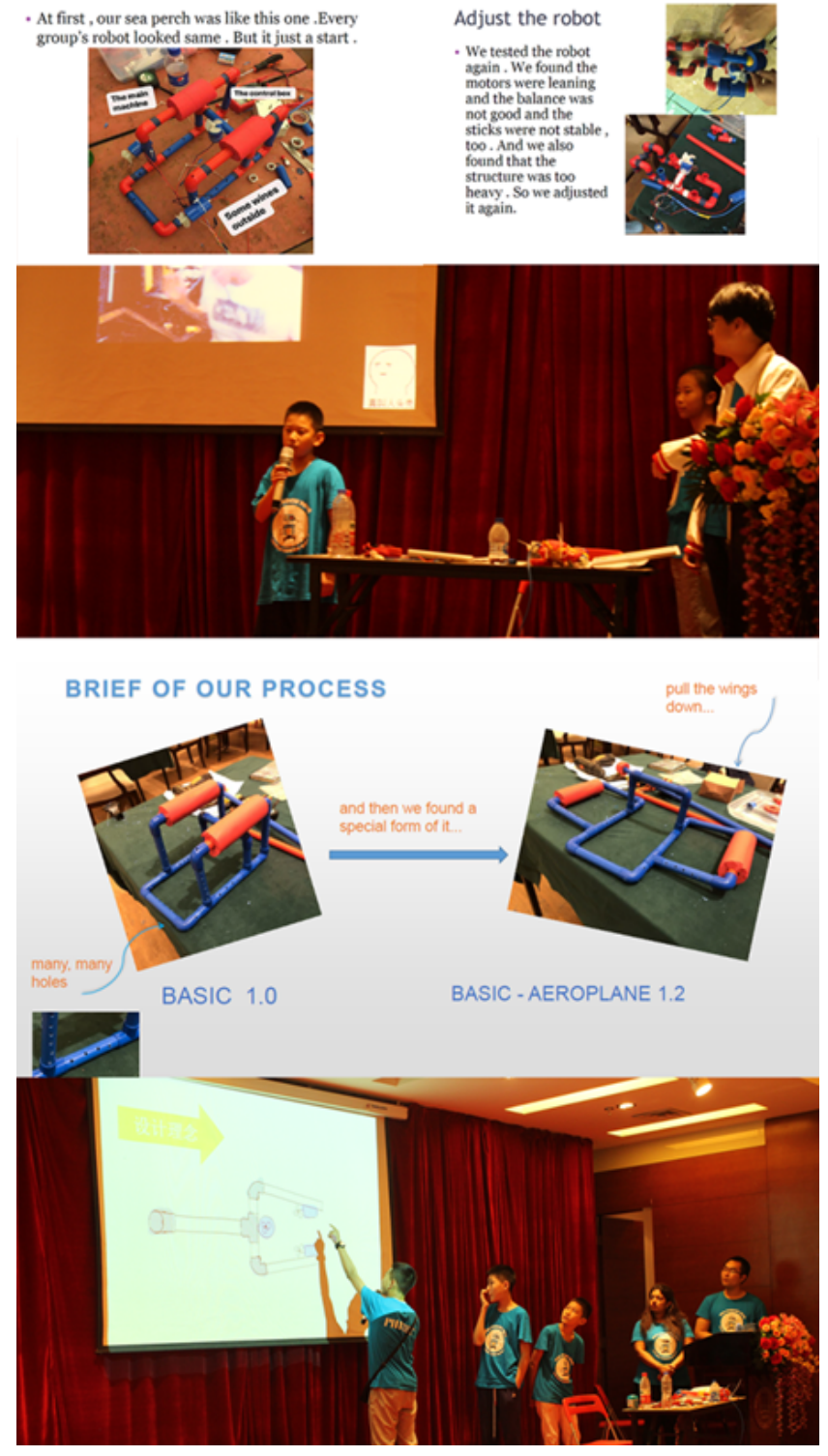

Fig. 8. Photos of the students' presentation and samples of the students slices.

Another critical point for the Chinese students in this camp is the last day showcase time. The evaluation of Chinese education focuses typically on the examination, as students focus on learning the knowledge. However, in the camp, as part of the evaluation, we provided students a platform to share their experience of the intensive activities during the camp time. To our big surprise, the students were full of passion for their showcase (shown in Fig. 8). Each group eagerly explained their way of design from the basic version to updated ones, for example, how to improve the efficiency of the thruster. Besides, we noticed that students not only share their experience of success, but most of them also pay strong emphasis on their experience of failure and how they were able to learn from the experience and came up with the solutions to overcome the obstacles. Furthermore, almost every group shares their vision for the future in the design that might be implemented in future technology to solve some ocean pollution problems. Such a case convinced us that the ending of this short-time camp would not be the end of the project for the students, and we believed the 
students would take this experience home and apply in their future study.

\section{CONCLUSION}

In this paper, we describe a new concept and the corresponding framework to implement the "STEM 3.0" teaching method to address the challenges and opportunities of STEM education in China. An example of a large scale 2019 underwater robot summer camp in Shanghai, featuring the use of sea perch underwater robots, is given as a demonstration of the successful test of the method.

In the camp, we found even in a short period of time, by building a standard "Sea Perch" underwater robots, Chinese students were able to be highly engaged in a project-based hands-on learning experience and acquire the necessary theoretical and practical knowledge. By assigning a task to encourage the students to address a simulated real-world task, students were motivated to integrate their knowledge and experience to come up with their solutions to the problem. The positive feedback from the students, teachers, and parents manifests the feasibility of using "STEM 3.0" learning and teaching methods to encourage Chinese students to convert from traditional knowledge learning to knowledge using style.

\section{ACKNOWLEDGEMENT}

Authors would like to give special thanks to OneSmart International Education Group and Mrs. Luna Liu for the endless support to facilitate this research.

\section{REFERENCES}

[1] B. H. Wells, H. A. Sanchez, and J. M. Attridge, "Modeling student interest in science, technology, engineering and mathematics," Meeting the Growing Demand for Engineers and Their Educators 2010-2020 International Summit, 2007.

[2] S. Makhmasi, R. Zaki, H. Barada and Y. Al-Hammadi. "Students' interest in STEM education," IEEE Global Engineering Education Conference, 2012.
[3] S. Ros, L. Tobarra, A. Robles-Gomez, et al. "Work in progress: On the improvement of STEM education from preschool to elementary school," IEEE Global Engineering Education Conference, 2016.

[4] D. Kotsifakos , B. Kostis and C. Douligeris . "Science, technology, engineering and mathematics (STEM) for vocational education in Greece," IEEE Global Engineering Education Conference, 2017.

[5] R. Burbaite, V. Drasute and V. Stuikys. "Integration of computational thinking skills in STEM-driven computer science education," IEEE Global Engineering Education Conference, 2018.

[6] C. T. Delistavrou and A. Kameas. "Exploring ways to exploit UMI technologies in STEM education: Comparison of secondary computer science curricula of Greece, Cyprus and England," IEEE Global Engineering Education Conference, 2017.

[7] P. P. Merino, E. Sancristobal, G. C. Fernandez and M. Castro. "Homemade robotic education, a new way to explore," IEEE Global Engineering Education Conference, 2017.

[8] L. Knop, S. Ziaeefard, G. A. Ribeiro and B. R. Page. "A humaninteractive robotic program for middle school STEM education," IEEE Frontiers in Education Conference, 2017.

[9] S. Karaman, A. Anders, M. Boulet and J. Connor. "Project-based, collaborative, algorithmic robotics for high school students: Programming self-driving race cars at MIT," IEEE Integrated STEM Education Conference, 2017.

[10] E. Markvicka, S. Rich, J. Liao and H. Zaini. "Low-cost wearable humancomputer interface with conductive fabric for STEAM education," IEEE Integrated STEM Education Conference, 2018.

[11] Scenes from the most important test in China. China Daily, 2017. http://www.chinadaily.com.cn/interface/zaker/1143609/2017-0608/cd_29673286.html.

[12] Chinese STEM education white paper (中国 STEM 教育白皮书). National Institute of Education Sciences, 2017.

[13] S. Yinxia and Q. Ailing. "Domestic research review of STEM education based on content analysis view," China educational technology \& equipment, 2017

[14] H. Dong and M. Bai. "Research on the development of STEM education in science and Engineering in China (中国理工科 STEM 教育发展探究), ” Modern Educational Technology, 2016, vol.7, pp.12-17.

[15] Report on STEM education in China (中国 STEM 教育调研报告), China National Institute of Education Sciences, 2019. http://www.nj13z.cn/News/Details/117548

[16] P. E. Gray. "Harold E. Edgerton," Physics Today, 1991, vol. 44, pp. 126128.

[17] Don't let them know they're learning, MIT Edgerton Center, 2014. https://edgerton-dev.mit.edu/file/dont-let-them-know-theyre-learning-0.

[18] H. Bohm, V. Jensen, and N. Johnston. Build your own underwater robot and other wet projects. Westcoast Words, 1997. ISBN: 0968161006.

[19] MIT sea grant educational programs, https://seagrant.mit.edu/education/. 